\title{
Alterations in cognitive performance and affect-arousal state during fluctuations in motor function in Parkinson's disease
}

\author{
RG BROWN, CD MARSDEN, N QUINN, MA WYKE \\ From the Departments of Psychology and Neurology, Institute of Psychiatry, University of London, \\ London, UK
}

SUMMARY Sixteen patients with idiopathic Parkinson's disease were selected who were all showing severe fluctuations in motor function ("on-off" phenomenon). Measures of cognitive function and of subjective affect/arousal state were taken on two occasions, once when "on" and once when 'off'. Twenty-five matched normal controls were also assessed on the same measures. Results revealed, on the average, a drop in cognitive function plus an adverse swing in affect/ arousal state, in the patient group in the "off' condition, compared to the levels when "on". Analysis of the data suggested that the main factor associated with cognitive function when "off" was not the severity of disability but the level of affect/arousal. The fluctuations in cognitive function found tended to be mild relative to the severe changes in motor ability, and were present in only a proportion of patients.

Research into the neuropsychology of Parkinson's disease over the last two decades has provided an extensive body of evidence on the cognitive deficits associated with this disease. Apart from generalised intellectual deterioration of the type found in dementia, other more subtle, specific deficits have been observed in some patients in areas such as memory, ${ }^{1-3}$ language, ${ }^{4}$ spatial orientation, ${ }^{56}$ concept formation ${ }^{7}$ and pattern matching. ${ }^{8}{ }^{9}$

Speculation as to the cause of these specific deficits has centred around two main arguments. First, are the deficits observed the result of dysfunction in the same subcortical structures which are responsible for the motor abnormalities of the disease? Second, are the deficits the result of concomitant cortical damage, present in at least a proportion of cases? While somewhat artificially polarising the debate, these two views still represent the main standpoints regarding the relationship between Parkinson's disease and cognitive function. However, increasing knowledge of both the neuroanatomy and the neuropathology of the disease is forcing a

Address for reprint requests: Mr RG Brown, Department of Neurology, Institute of Psychiatry, De Crespigny Park, London SE5 8AF, England.

- Received 5 August 1983 and in revised form 15 November 1983. Accepted 23 November 1983 change in emphasis from the crude cortical/ subcortical debate.

The key neuropathological substrate of Parkinson's disease is a degeneration of the zona compacta of the substantia nigra which contains the cell bodies of the dopaminergic nigrostriatal pathway..$^{10}$ But the disease also involves another group of dopamine producing cells in the adjacent ventral tegmental area. ${ }^{11}$ Together, these two regions provide the dopaminergic input to the brain's three main dopamine systems, the nigrostriatal, mesolimbic and mesocortical systems. The striatum receives its dopaminergic input almost exclusively from the substantia nigra. ${ }^{12}$ Dopamine innervation of "limbic" structures such as the nucleus accumbens and hypothalamus originates from both the substantia nigra and the ventral tegmental area. ${ }^{1314}$ Some areas of the frontal and entorhinal cortex receive fibres of the mesocortical dopamine system which originate mainly from the ventral tegmental area. ${ }^{14}$ All three main dopaminergic pathways are affected in Parkinson's disease..$^{1} 11$ is As a result, the cortical/ subcortical distinction is an over-simplification. Pathological changes in subcortical nuclei involve not just other subcortical structures and processes, but also certain discrete cortical areas as well.

Starting from the cortical end of the debate, a similar blurring of the distinction can be observed. Post-mortem examination of the brains of patients 
with Parkinson's disease reveals, in some cases, pathological changes of the type found in Alzheimer's disease. ${ }^{16-18}$ Evidence from computed tomography, ${ }^{19}$ pneumoencephalography, ${ }^{20}$ and cerebral blood flow studies, ${ }^{21}$ also reveal the existence of cortical changes in the brains of a proportion of patients with Parkinson's disease. In Alzheimer's disease, evidence is increasingly pointing to the importance of pathological processes in the cholinergic neuron systems arising in subcortical structures. The evidence suggests that a key role is played by basal forebrain structures in the substantia innominata, in particular the nucleus basalis of Meynert, ${ }^{22}{ }^{23}$ which is the main source of the ascending cholinergic system innervating the cerebral cortex. Pathological changes in this structure are found not just in Alzheimer's disease, but also in the brains of a proportion of patients with Parkinson's disease. ${ }^{24} 25$

These changes in cholinergic input to the cerebral cortex have been linked to the presence of clinically recognisable dementia in Parkinson's disease. While estimates vary, it is generally found that about $30 \%$ of such patients will eventually become demented. ${ }^{26}{ }^{27}$ Whether the subtle and relatively specific cognitive deficits listed earlier precede and/ or have any qualitative similarities with dementia remains to be seen. Nevertheless, the possibility exists that changes in cortical cholinergic function may in some way contribute to the pattern of cognitive impairment seen in even clinically nondementing Parkinsonians.

Thus it seems that cortical and subcortical changes are inexorably linked in both Parkinson's disease and Alzheimer's disease. So the cortial-subcortical debate now is an inadequate basis for separation of the crucial factors underlying the cognitive impairment seen in Parkinson's disease. Instead, it might be better to ask the question: "What role does the multisystem dopaminergic disturbance of Parkinson's disease play in the manifestation of cognitive impairment in that illness?" While focusing on a single neurochemical system might itself be accused of being an over-simplification, the approach has the advantage of generating more testable hypotheses than the cortical/subcortical distinction.

Indirect evidence on the role of dopaminergic systems in cognitive function in Parkinson's disease can be found from two main sources. First, there are the many studies which have shown an improvement in either general or specific cognitive function following commencement of levodopa therapy, at least in the short term and in a non-demented Parkinsonian population. ${ }^{78-30}$ Second, there are those studies which have found a positive relationship between the severity of the motor symptoms of Parkinson's disease and the severity of cognitive dysfunction..$^{41-34}$ Both of these strands of evidence might be taken as supporting the hypothesis that the dopamine system is playing some role, direct or indirect, in cognitive function.

The present study is intended as a further test of this dopamine hypothesis. It utilises the "on-off" phenomenon that develops in a proportion of patients with Parkinson's disease during long-term levodopa treatment. This is a condition in which the patient's motor function fluctuates markedly from near normal at some times ("on" condition) to severe Parkinsonian motor disability at others ("off" condition). ${ }^{35}$ Given the known relationship between the motor signs of the disease, and the level of striatal dopamine, ${ }^{10}$ the "on-off" fluctuations must represent a situation where the functional dopamine levels in the striatum are fluctuating wildly from one extreme to the other. Furthermore, it is parsimonious to assume that such fluctuations also occur at the same time in the mesocortical and mesolimbic systems as well, although this is unproven. In such a situation one would also expect to find fluctuations in the individual's level of cognitive function, if that cognitive function is dependent upon the functional integrity of the dopamine system. However, other factors may also play a role in such a situation. In particular, the individual's levels of arousal, alertness, mood and motivation also may fluctuate with changes in motor state. The alerting or "awakening" effect of levodopa has been noticed by clinicians from the advent of treatment..$^{36-38}$ The abnormal incidence of affective disorder in Parkinson's disease, ${ }^{39-41}$ even compared with other disabling illnesses, has led many to speculate that such changes are in inherent part of the disease, just as much as the motor impairment. However, few authors have attempted to integrate such factors into their models of cognitive dysfunction of Parkinson's disease. One exception to this is Riklan ${ }^{42}$ who, in discussing the psychological consequences of levodopa therapy, considered that "the critical behavioural alteration... is an increase in behavioural activation or arousal". So, changes in arousal, alertness and mood need to be measured, and their contribution to the pattern of cognitive impairment assessed, before conclusions can be drawn as to the nature of any underlying cognitive deficit in Parkinson's disease.

The present study investigated the changes in arousal, mood and cognitive function that occur in a group of patients with Parkinson's disease experiencing dramatic swings of mobility from good to bad during chronic levodopa therapy. Changes in standardised measures of arousal, mood and cognitive function have been measured during mobile 
Table 1 Disease factors for patients with Parkinson's disease $(n=16)$

\begin{tabular}{lllllll}
\hline & $\begin{array}{l}\text { Age of onset } \\
\text { (years) }\end{array}$ & $\begin{array}{l}\text { Duration of } \\
\text { illness (years) }\end{array}$ & $\begin{array}{l}\text { Duration of } \\
\text { levodopa therapy } \\
\text { (years) }\end{array}$ & $\begin{array}{l}\text { Disability } \\
\text { score "On" }\end{array}$ & $\begin{array}{l}\text { Disability } \\
\text { score 'Off" }\end{array}$ \\
\hline Mean & $45 \cdot 1$ & $11 \cdot 2$ & $9 \cdot 0$ & $13 \cdot 2$ & $55 \cdot 9$ & $42 \cdot 7$ \\
SD & $9 \cdot 3$ & $4 \cdot 3$ & $2 \cdot 5$ & $6 \cdot 0$ & $15 \cdot 5$ & $13 \cdot 7$ \\
Range & $31-60$ & $5-19$ & $4-12$ & $1-23 \cdot 5$ & $32-81 \cdot 5$ & $15-62$ \\
\hline
\end{tabular}

Mean disability scores on the King's College Hospital Parkinson's disease rating are shown. This evaluates 39 symptoms and signs each on a 0 to 3 scale, where $0=$ normal, $1=$ mild, $2=$ moderate, and $3=$ severely affected. The maximum disability score is 117 . Patients with scores above 50 would be likely to be chair or bed-bound. Patients with scores below 10 would be only mildly affected.

"on" periods and immobile "off" periods, and the inter-relations between these variables have been studied.

\section{Method}

\section{A. Subjects}

Sixteen patients with idiopathic Parkinson's disease and twenty-five control subjects were studied. In both groups, subjects were excluded who showed clinical signs of dementia, psychotic illness or focal cortical pathology. All of the patients were being treated with levodopa, in most cases combined with carbidopa. In a few cases, other antiparkinsonian medication was also being administered. The majority of patients were seen during in-patient admission to the neurology wards of the Maudsley and King's College Hospitals.

All patients had bilateral symptoms and signs of Parkinson's disease, and were experiencing extreme "on-off" fluctuations before admission. The control subjects were either the relatives of patients attending the out-patient Parkinson's disease clinic, or were volunteer members of a subject panel.

\section{B. Measures}

(1) Neurological assessment All patients were seen by the same neurologist and were assessed using a standardised examination, rating 39 signs and symptoms of Parkinson's disease on a $0-3$ scale ( 0 indicating no impairment and 3 indicating severe impairment). A total disability score was obtained by summing all the ratings (maximum score 117). Each patient was assessed twice, once when "off' and once when "on". This was done in the same session as psychological testing, or as close as was practically poss- ible. Mean disability scores for the two occasions plus other relevant information on the Parkinson's disease group is given in table 1.

(2) Neuropsychological assessment A proportion of the patients $(12 / 16)$ and of the controls $(20 / 25)$ were given a short form of the Wechsler Adults Intelligence Scale (WAIS). ${ }^{43}$ Three verbal subtests were administered, vocabulary, similarities and comprehension, from which a verbal IQ score was calculated (see table 2$).{ }^{44}$ These subtests were used, not to screen for dementia, but to obtain an estimate of general intellectual function. This assessment was conducted in the Parkinson's disease group while they were "on".

The neuropsychological test instrument used for the "on-off' comparison, was a test of general reasoning ability for verbal, numerical and spatial material. The test was adapted from those of Heim, the AH4 and AH5.45 The test will be known as the Modified Alice Heim Test (MAHT). The Heim tests were ideal for the purpose of the present study, as most questions were presented with multiplechoice answers. This greatly reduced the response demands made on the subject, which was necessary if motor disability was not going to confound test results.

The MAHT was devised by combining a selection of items from the AH4 and AH5 (which cover different ability ranges). From this composite, items of the same type, format and judged level of difficulty were paired, and items from each pair randomly assigned to either form $A$ or form $B$ of the test, thus providing two balanced, equivalent measures. Each form contained 79 items (38 verbal numerical, and 41 visuospatial). A further set of 15 items from the AH4 and AH5 were used as examples to illustrate each of the question types in the full form. This set of questions is given in Appendix $\mathbf{I}$.

Table 2 Age, education and IQ: Parkinson and control groups

\begin{tabular}{|c|c|c|c|c|c|c|c|}
\hline & & $\begin{array}{l}\text { Age } \\
\text { (years) }\end{array}$ & $\begin{array}{l}\text { Education } \\
\text { (years) }\end{array}$ & $\begin{array}{l}\text { Verbal } \\
I Q^{*}\end{array}$ & $\begin{array}{l}\text { Comprehension* } \\
\text { (scaled score) }\end{array}$ & $\begin{array}{l}\text { Similarities * } \\
\text { (scaled score) }\end{array}$ & $\begin{array}{l}\text { Vocabulary* } \\
\text { (scaled score) }\end{array}$ \\
\hline $\begin{array}{l}\text { Parkinson group } \\
(n=16) \\
\text { Male:female }=3 \cdot 25: 1\end{array}$ & $\begin{array}{l}\text { Mean } \\
\text { SD } \\
\text { Range }\end{array}$ & $\begin{array}{c}56 \cdot 3 \\
9 \cdot 8 \\
39-73\end{array}$ & $\begin{array}{l}11 \cdot 8 \\
2 \cdot 9 \\
9-16\end{array}$ & $\begin{array}{l}116 \cdot 6 \\
14 \cdot 1 \\
98-139\end{array}$ & $\begin{array}{l}23 \cdot 2 \\
2 \cdot 4 \\
10-16\end{array}$ & $\begin{array}{l}11 \cdot 9 \\
2 \cdot 3 \\
9-15\end{array}$ & $\begin{array}{c}14 \cdot 0 \\
2 \cdot 5 \\
10-16\end{array}$ \\
\hline $\begin{array}{l}\text { Control group } \\
(n=25) \\
\text { Male:female }=1 \cdot 20: 1\end{array}$ & $\begin{array}{l}\text { Mean } \\
\text { SD } \\
\text { Range }\end{array}$ & $\begin{array}{l}57 \cdot 6 \\
12 \cdot 9 \\
42-74\end{array}$ & $\begin{array}{l}10 \cdot 2 \\
2 \cdot 7 \\
9-16\end{array}$ & $\begin{array}{l}121 \cdot 1 \\
11 \cdot 0 \\
98-143\end{array}$ & $\begin{array}{l}14 \cdot 5 \\
2 \cdot 2 \\
10-18\end{array}$ & $\begin{array}{l}12 \cdot 5 \\
2 \cdot 9 \\
4-16\end{array}$ & $\begin{array}{c}14 \cdot 4 \\
2 \cdot 3 \\
11-17\end{array}$ \\
\hline
\end{tabular}

*Parkinson group $n=12$, control group $n=20$. 
In order to facilitate administration, each test item was presented individually on a white card measuring $30 \times$ $7 \mathrm{~cm}$. The cards were presented in turn to the subject, while being read out at the same time, by the experimenter. There was no formal time limit for each question, but if the subject failed to answer within two minutes they were pressed for a response. Two response measures were taken: accuracy (correct or incorrect) and time taken to respond.

(3) Assessment of subjective "affect-arousal" This measure consisted of a series of $16,100 \mathrm{~mm}$ analogue scales, developed for the assessment of subjective response to anti-anxiety and antidepressant drugs. ${ }^{46}$ Each of the 16 scales contained a pair of bipolar adjectives such as “happy-sad" or "alert-drowsy" (see Appendix II for the full 16 scales). The subject's task was to indicate on the line separating these adjectives, the position which they considered to best describe their present state.

Some of the scales were unsuitable for assessment of subjective affect/arousal, as they would load heavily on the motor impairment of Parkinson's disease. These three scales, "well coordinated-clumsy", "strong-feeble" and "tense-relaxed", were not taken into account when calculating a global "Subjective Affect/Arousal Score", based on the mean response for the remaining 13 scales. With the final measure, a high score represents a state of negative or adverse affect/arousal.

\section{Procedure}

As patients became available, they were alternately assigned to one of two groups to be tested in either the "on" or the "off" condition first. Within each group, half received form A of the MAHT first, and half received form $B$. The subject was first given the 15 example items and every effort was made to ensure that the subject understood each question and answer. No further help was given with the main form of the test.

Immediately prior to, and following administration of, each form of the MAHT, the subject completed the subjective affect/arousal scales.

Some patients were seen on a third occasion, for administration of the three subtests from the WAIS.

Assessment in the "on" condition was conducted when the patient's motor state was optimal and usually presented few problems. Timing the "off" period was more difficult. In some cases, the "on-off" fluctuations were reasonably predictable, and testing could be timed to fit in with that pattern. However, in other cases (approximately 50\%) the "off' periods were unpredictable, both in terms of timing and duration. In such cases, assessment was conducted either during a period of therapeutic withdrawal of medication, or following temporary withholding of normal medication, normally first thing in the morning.

For the control subjects, assignment was to one of two conditions, either to receive form $A$ or form $B$ of the MAHT first. The methods of administration and scoring were identical to those used for the patients. Similarly, two measures of affect/arousal were taken in each session. For those control subjects who also received the WAIS subtests, assessment took place at the end of the second session.

\section{Results}

Information on the make-up of the Parkinson's disease group and control group is shown in table 2. There was no significant difference between their mean ages $(t=-0.33)$ or mean number of years of education $(t=1 \cdot 18)$. The mean verbal IQ of the control group was 4.5 points higher than that of the patient group, although this result was not significant $(t=0.90)$. The differences in mean scores for the comprehension $(t=-1 \cdot 60)$, similarities $(t=-0.62)$ or vocabulary subtests $(t=-0.46)$ also were not different between patients and controls.

The purpose of the age-matched control group was two-fold. First, to check that the two forms of the MAHT were equivalent, and second to serve as a comparison for the Parkinson's disease group.

Comparing the control groups' performance on the two forms of the MAHT confirmed that they could be considered "parallel" for present purposes. For form A, the mean accuracy score was $75.9 \%$ (SD 10.2), and total time was 1256 seconds (SD 580). For form B, mean accuracy was $75.6 \%$ (SD 10.2), and total time was 1276 seconds (SD 564). For the 25 subjects the correlations between their performance on the two forms was for accuracy $0 \cdot 89$, and for time $0 \cdot 88$. There was evidence of a slight but non-significant practice effect between the two sessions. However, because of the balanced design of the study, this would not influence results.

For the control group, the average accuracy and time scores for the two sessions were calculated for each subject, and it is these scores which served as the comparison for the Parkinson's disease group.

With the results from the affect/arousal scales, no significant difference was found between the scores obtained before and after each session, for either the controls $(t=0 \cdot 17)$, the Parkinson's disease group "on" $(t=0.24)$, or the Parkinson's disease group "off" $(t=1.57)$. This suggests that the variables being measured by the scales were relatively stable across the hour which each session lasted. This implies that any changes in scores were not in reaction to the MAHT itself. Because of the within session stability of the affect/arousal measure, the pretest and post-test scores were combined to give an average subjective affect/arousal score. In the case of the control group, the measure appeared to be stable across as well as within sessions, and consequently a single, averaged score was calculated for each control subject.

Table 3 shows the mean MAHT and subjective affect/arousal scores for the different groups. A number of comparisons were carried out between the control group and the Parkinson's disease group 
Table 3 Results from Modified Alice Heim Test (MAHT) and Subjective Affect/Arousal Score in Parkinson's disease and control groups

\begin{tabular}{|c|c|c|c|c|}
\hline & & MAHT accuracy (\%) & MAHT time (s) & $\begin{array}{l}\text { Subjective affect/arousal } \\
\text { score }\end{array}$ \\
\hline $\begin{array}{l}\text { Control group } \\
(\mathrm{n}=25)\end{array}$ & $\begin{array}{l}\text { Mean } \\
\text { SD } \\
\text { Range }\end{array}$ & $\begin{array}{l}75 \cdot 8 \\
10 \cdot 0 \\
54 \cdot 1-90 \cdot 6\end{array}$ & $\begin{array}{l}1267 \\
555 \\
563-3099\end{array}$ & $\begin{array}{c}43 \cdot 3 \\
8 \cdot 3 \\
21-54\end{array}$ \\
\hline $\begin{array}{l}\text { Parkinson group } \\
\text { "On” } \\
(n=16)\end{array}$ & $\begin{array}{l}\text { Mean } \\
\text { SD } \\
\text { Range }\end{array}$ & $\begin{array}{l}67 \cdot 4 \\
12 \cdot 7 \\
45 \cdot 6-88 \cdot 6\end{array}$ & $\begin{array}{l}1254 \\
473 \\
521-2052\end{array}$ & $\begin{array}{l}51 \cdot 1 \\
10 \cdot 5 \\
29-67\end{array}$ \\
\hline $\begin{array}{l}\text { Parkinson group } \\
\text { "Off” } \\
(n=16)\end{array}$ & $\begin{array}{l}\text { Mean } \\
\text { SD } \\
\text { Range }\end{array}$ & $\begin{array}{l}61 \cdot 3 \\
13 \cdot 4 \\
40 \cdot 5-81 \cdot 0\end{array}$ & $\begin{array}{l}1086 \\
548 \\
612-2428\end{array}$ & $\begin{array}{l}58 \cdot 9 \\
15 \cdot 9 \\
31-87\end{array}$ \\
\hline $\begin{array}{l}\text { Statistics: } \\
\text { 1. Controls -v- PD “on”* } \\
\text { 2. PD “on" -v- PD “off”+ }\end{array}$ & & $\begin{array}{l}(t=-2.25 \text { df }=26.6) \\
p<0.05 \\
(t=3.88 \text { df }=15) \\
p<0.01\end{array}$ & $\begin{array}{l}(\mathrm{t}=-0.07 \mathrm{df}=35 \cdot 7) \\
\mathrm{NS} \\
(\mathrm{t}=1 \cdot 15 \mathrm{df}=15) \\
\text { NS }\end{array}$ & $\begin{array}{l}(t=2.51 \text { df }=26.9) \\
p<0.02 \\
(t=-2.14 \text { df }=15) \\
p<0.05\end{array}$ \\
\hline
\end{tabular}

${ }^{*} t$-test for independent samples. Separate variance estimates.

†Paired $t$ test.

in the "on" condition. Independent $t$ tests were used with separate variance estimates. The mean MAHT accuracy score for the Parkinson's disease group when "on" $(67.4 \%)$ was significantly less than for the controls $(75 \cdot 8 \%)(\mathrm{t}=-2 \cdot 25, \mathrm{df}=26 \cdot 6, \mathrm{p}<$ $0 \cdot 05$ ), although there was no significant difference between the total times taken to complete the test (1254 and 1267 seconds respectively) $(t=-0.07, \mathrm{df}$ $=35.7)$. The mean subjective affect/arousal score of the Parkinson's disease group when "on" (51.1), was significantly higher than that of the controls $(43.3)(t=2 \cdot 51, \mathrm{df}=26.9, \mathrm{p}<0.02)$. A high score reflects an adverse affect/arousal state. Similar comparisons were carried out between the Parkinson's disease group under the two conditions, this time using paired $t$ tests. The mean MAHT accuracy score showed a significant decrease in the "off" condition $(61.3 \%)(\mathrm{t}=3.88, \mathrm{df}=15, \mathrm{p}<0.01)$. While mean time taken to complete the test decreased to 1086 seconds, the difference was not statistically significant $(t=1 \cdot 15$, df $=15)$. Results from the subjective affect/arousal scale, showed a significant increase (that is, deterioration) when "off", with a mean score of $58.9(\mathrm{t}=-2 \cdot 14, \mathrm{df}=15, \mathrm{p}<0.05)$.
The relationships between the various factors which might influence MAHT performance in the different groups then was considered. A simple model of functional cognitive capacity in a normal individual might include three related factors: that individual's basic intellectual ability, their age, and their current state of affect/arousal. The correlations between these three factors and the performance variables of the MAHT in the control group are given in table 4 . From this it can be seen that neither age nor affect/arousal were significantly associated with MAHT accuracy or time. By far the highest correlation was between test accuracy and VIQ $(r=$ 0.75 ), with the two variables sharing over $56 \%$ of common variance. It seems from this that in the control group, the MAHT provided a reasonable measure of the individual's intellectual ability, which was largely independent of both age and present-state affect/arousal.

The model for the Parkinson's disease group is more complex. At a minimum, two further factors need to be taken into account, namely the duration of the illness and the degree of Parkinsonian motor disability at the time of testing. The correlation mat-

Table 4 Correlation Matrix: Control Group $(n=20)$

\begin{tabular}{|c|c|c|c|c|c|}
\hline & $\begin{array}{l}\text { MAHT } \\
\text { time }\end{array}$ & Age & $\begin{array}{l}\text { Verbal } \\
I Q \ddagger\end{array}$ & $\begin{array}{l}\text { Years of } \\
\text { education }\end{array}$ & $\begin{array}{l}\text { Subject } \\
\text { affect/arousa }\end{array}$ \\
\hline $\begin{array}{l}\text { MAHT accuracy } \\
\text { MAHT time } \\
\text { Age } \\
\text { Verbal IQ } \dagger \\
\text { Years of education }\end{array}$ & 0.27 & $\begin{array}{l}0 \cdot 04 \\
0 \cdot 26\end{array}$ & $\begin{array}{c}0.75 \dagger \\
-0.08 \\
0.04\end{array}$ & $\begin{array}{c}0.38^{*} \\
-0.12 \\
0.15 \\
0.51^{*}\end{array}$ & $\begin{array}{r}0 \cdot 11 \\
-0 \cdot 08 \\
-0 \cdot 08 \\
0 \cdot 09 \\
-0 \cdot 21\end{array}$ \\
\hline
\end{tabular}

$* p<0.05$

$+\mathrm{p}<0.001$

$\neq \mathrm{n}=16$ 
Table 5 Correlation Matrix: Parkinson Group "On” $(n=16)$

\begin{tabular}{|c|c|c|c|c|c|c|c|}
\hline & $\begin{array}{l}\text { MAHT } \\
\text { time }\end{array}$ & Age & $\begin{array}{l}\text { Verbal IQ } \\
(\ddagger)\end{array}$ & $\begin{array}{l}\text { Years of } \\
\text { education }\end{array}$ & $\begin{array}{l}\text { Subjective } \\
\text { affect/arousal }\end{array}$ & $\begin{array}{l}\text { Degree of } \\
\text { disability }\end{array}$ & $\begin{array}{l}\text { Duration } \\
\text { of illness }\end{array}$ \\
\hline $\begin{array}{l}\text { MAHT accuracy } \\
\text { MAHT time } \\
\text { Age } \\
\text { Verbal IQł } \\
\text { Years of education } \\
\text { Subjective affect/arousal } \\
\text { Degree of disability }\end{array}$ & -0.03 & $\begin{array}{l}-0.20 \\
-0.04\end{array}$ & $\begin{array}{r}0.72 \dagger \\
0.17 \\
-0.14\end{array}$ & $\begin{array}{l}0.46^{*} \\
0.32 \\
0.01 \\
0.71 \dagger\end{array}$ & $\begin{array}{c}-0.24 \\
-0.03 \\
0.57 * \\
0.04 \\
-0.18\end{array}$ & $\begin{array}{r}-0.34 \\
-0.14 \\
0 \cdot 27 \\
-0 \cdot 48 \\
-0.39 \\
0.12\end{array}$ & $\begin{array}{l}-0.29 \\
0.08 \\
0.27 \\
0.01 \\
0.23 \\
0.10 \\
0.66 \dagger\end{array}$ \\
\hline
\end{tabular}

rix for the Parkinson's disease group when "on" is shown in table 5. As with the controls, the main association was between MAHT accuracy and VIQ, with neither age nor affect/arousal having any significant association with test performance. Taking duration of illness and degree of disability together, their multiple correlation with MAHT accuracy is only 0.35 , that is, the two variables only shared about $12 \%$ of the common variance with test performance.

One result which stands out is the observed positive relationship between age and affect/arousal ( $r=$ $0.57)$, which is in marked contrast to the control group, where the two variables were essentially unrelated $(r=-0.08)$. The significance of this finding is uncertain, and may represent the general effect of a chronic, disabling illness in an aging population. ${ }^{478}$ Apart from the relationship between age and affect/arousal, the Parkinson's disease group when "on" behaved in much the same way as the controls, with intellectual ability (as assessed by the WAIS) seeming to be the main determinant of MAHT accuracy, and with age, affect/arousal and, in the patients' case, disease factors, having relatively little association with performance.

When considering the Parkinson's disease group in the "off" condition a very different picture is seen (see table 6). While VIQ was still a significant factor, its association with MAHT accuracy had decreased. Age and duration of illness were still relatively unimportant, but now, in contrast to the "on" condition MAHT accuracy was significantly associated with the degree of disability $(r=-0.51)$ and with affect/arousal $(r=-0.68)$.

In order to examine the relationship between these factors in more detail, a standard multiple regression analysis was conducted using the SPSS REGRESSION package. ${ }^{49}$ The accuracy score on the MAHT in the "off" condition was taken as the dependent variable, with disability score and affect/ arousal score (again when "off') as the independent variables. The multiple correlation $(R)$ of these two variables was $0.73(\mathrm{~F}(2,13)=7 \cdot 19, \mathrm{p}<0.01)$. In other words, disability and affect/arousal together predicted $52.5 \%$ of the variation in MAHT accuracy score $\left(R^{2}=0.525\right)$. Next, to examine the relative "importance" of the independant variables as predictors of the dependent variable, squared semipartial correlations $\left(\mathrm{sr}^{2}\right)$ were calculated. ${ }^{50}$ This gives a measure of the unique contribution of each independent variable as a proportion of the total variability of the dependent variable. In the case of affect/arousal the $\mathrm{sr}^{2}$ was $0.26(\mathrm{p}<0.02)$. In contrast, disability failed to make any significant unique contribution $\left(\mathrm{sr}^{2}=0.06\right)$. Thus it can be seen of the two independent variables studied, only affect/ arousal made any significant contribution to the variability of MAHT accuracy when considered independently. This further suggests that the relatively high simple correlation between disability and

Table 6 Correlation Matrix: Parkinson Group “off” $(n=16)$

\begin{tabular}{|c|c|c|c|c|c|c|c|}
\hline & $M A H T$ & Age & $\begin{array}{l}\text { Verbal } \\
I^{\dagger}\end{array}$ & $\begin{array}{l}\text { Years of } \\
\text { education }\end{array}$ & $\begin{array}{l}\text { Subjective } \\
\text { affect/arousal }\end{array}$ & $\begin{array}{l}\text { Degree of } \\
\text { disability }\end{array}$ & $\begin{array}{l}\text { Duration } \\
\text { of illness }\end{array}$ \\
\hline $\begin{array}{l}\text { MAHT accuracy } \\
\text { MAHT time } \\
\text { Age } \\
\text { Verbal IQ } \ddagger \\
\text { Years of education } \\
\text { Subjective affect/arousal } \\
\text { Degree of disability }\end{array}$ & -0.02 & $\begin{array}{r}-0.29 \\
0.27\end{array}$ & $\begin{array}{c}0.50^{*} \\
0.23 \\
-0.14\end{array}$ & $\begin{array}{l}0.44^{*} \\
0.54^{*} \\
0.01 \\
0.71 \dagger\end{array}$ & $\begin{array}{c}-0.68 \dagger \\
-0.01 \\
0.38 \\
0.20 \\
-0.23\end{array}$ & $\begin{array}{c}-0.51 * \\
0.10 \\
0.10 \\
-0.24 \\
-0.29 \\
0.41\end{array}$ & $\begin{array}{r}-0.37 \\
0.05 \\
0.27 \\
0.01 \\
-0.23 \\
0.49^{*} \\
0.46^{*}\end{array}$ \\
\hline
\end{tabular}

${ }^{*} \mathrm{p}<0.05$

$+\mathrm{p}<0.01$
$\ddagger \mathrm{n}=12$ 
MAHT accuracy was largely mediated by the affect/arousal state.

To summarise the key results: (1) The Parkinson's disease group when "on" were imparied on two factors compared to the controls, MAHT accuracy and subjective affect/arousal, (2) Further deterioration (and of about the same magnitude) was seen when comparing the Parkinson's disease group when "off" with their scores when "on", (3) For both the control group, and the Parkinson's disease group when "on", VIQ was the only factor significantly associated with MAHT accuracy, (4) In the Parkinson's disease group when "off", the size of the IQ-MAHT association decreased, with the main relationship being with affect/arousal. While degree of disability was significantly associated with MAHT accuracy, the relationship seemed to be mediated via the changes in affect/arousal, (5) Neither age nor duration of ilness in the Parkinsonian patients seemed to be important variables, either "on" or "off".

\section{Discussion}

The first finding which needs to be discussed is the slight but significant impairment in cognitive performance (as measured by MAHT accuracy) of the Parkinson's disease group when "on" (and it must be assumed, optimally treated) compared to the control group. There is also the tendency for the Parkinson's disease group to have lower VIQ scores, despite the two groups being matched for both age and years of education.

The nature or cause of this impairment is uncertain. It seems to be unrelated to any single factor measured, namely age, education, degree of disability, duration of illness or any disturbance of affect/ arousal. It may be that merely choosing age and years of education was inadequate to ensure that the two groups were matched with regard to current cognitive ability. Alternatively, it could be that the differences between the two groups represent a true cognitive change in the Parkinson's disease group, the cause of which can only be determined by adopting a multifactorial model. Unfortunately this is beyond the scope of a study with a sample of this size.

In the Parkinson's disease group in the "off" condition, the relationship between degree of disability and cognitive function seems to confirm the finding of previous studies ${ }^{41-34}$ and to support the hypothesis that dopamine levels (at least in the striatum) are an important factor associated with cognitive function. However, as has been seen, in the present study at least, this association tends to be largely mediated via adverse changes in affect/ arousal. This finding must inevitably cast some doubt upon the conclusions that have been drawn from earlier studies which have found relationships between the severity of cognitive and motor impairment, and those which have found improved cognitive performance with levodopa therapy.

Deliberate care has been taken, so far, not to suggest causal relationships between the various factors found to be associated in the present study. Premature causal models have the tendency to take on rapidly an air of "fact". Nevertheless, some open speculation on the results from the present study might be in order. A plausible hypothesis is that the functional cognitive impairment seen in Parkinson's disease when "off' is a direct result of disturbances in affect/arousal. However, while plausible, this is not the only possible explanation for the association. It is possible that the disturbances in cognitive function and affect/arousal are essentially independent, but that both variables are causally related to a third factor. A possible candidate for such a factor is the functional integrity of a neurochemical system. It would seem from present results that striatal dopamine levels are not strongly implicated. However, this does not exclude the mesocortical and/or the mesolimbic systems. Clearly, it would be crucial to know the extent to which the observed changes in affect/arousal are the result of endogenous neurochemical fluctuations, and the extent to which they are reactive to the huge increase in motor disability. While it is a crucial question, it is difficult at present to see how it might be answered with the techniques available.

A logical question to ask is "Is there any pattern in the deficits in MAHT performance shown by the Parkinson's disease group in the "off'condition?". Analysis of the questions passed and failed under the two conditions, revealed that the Parkinson's disease group when "off" seemed to be generally worse on a wide range of question types, verbal, numerical and spatial. The only question type which came close to discriminating the two groups was that illustrated by Example (a) in Appendix I. This sort of question required complex verbal reasoning. It is interesting that Matison $\mathrm{et} \mathrm{al}^{4}$ recently suggested a specific deficit in semantic access to the internal lexicon in Parkinson's disease.

The present study, in common with most studies of its kind, utilised the techniques of comparing the mean performances of two groups (in this case, controls with Parkinsonians), or the same group on two occasions (Parkinsonians "on" and "off'). The conclusions which are typically drawn from such studies are based on the implicit assumption that the members of each group are drawn from a homogeneous population. Nevertheless, this assumption is some- 


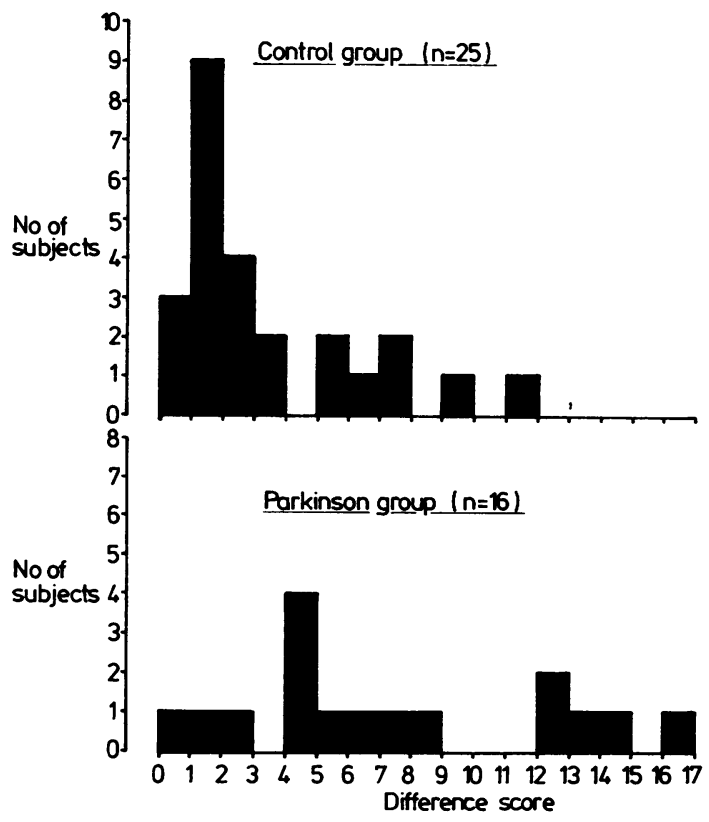

Fig 1 Histogram of the differences in MAHT accuracy scores in (a) the control group between the two test occasions, (b) the Parkinson's disease group between testing when "on" and testing when "off".

times inaccurate with the result that simply comparing group means may lead to inaccurate conclusions being drawn about the whole sample (and by extrapolation, to the whole population). In the present case, the results suggest that, on average, the Parkinson's disease group when "off' perform in a test of cognitive function less well than when "on", for whatever reason. Is this in fact true for the group as a whole?

Figure 1a shows the difference in accuracy scores on the two forms of the MAHT for the 25 control subjects. It can be seen that most subjects had a difference of no more than four points between their performance on the two occasions, and in no case was the difference greater than 11 points. Figure $1 \mathrm{~b}$ shows the difference scores for the Parkinson's disease group's MAHT accuracy, "on" and "off". Although the sample is small, there is nevertheless a suggestion of bimodality in the distribution, with the majority of subjects showing a similar magnitude of difference to that found in the control group, while about $30 \%$ show differences exceeding the maximum found in any of the controls. For descriptive purposes, these two subgroups of Parkinson's disease subjects can be called the "High Change" group (alteration of 12 or more points which occurred in five patients), and the "Low Change" group (alteration of less than 12 points which occurred in 11 patients). Data on them is provided in table 7. Because of the small sample sizes, the statistics should be interpreted with caution and a degree of scepticism. Nevertheless, there seems to be a tendency for the "High Change" group to be slightly older, be more disabled and to have had Parkinson's disease for slightly longer, although in no instance are any of these differences statistically significant. In fact, the only significant difference between the two groups is the severity of the adverse affect/ arousal change when in the "off' condition. However, these changes are clearly not the only contributory factor. Several members of the Low Change group showed affect/arousal scores as great or greater than those of some of the High Change group, once again suggesting that multiple factors are contributing to the functional changes shown between the "on" and "off" conditions.

It can be seen from table 7 and fig 1 that the patients in the "high change" group experienced an equal range of increase in disability between the "on" and "off" states, to those patients in the "low change" group. This is emphasised in fig 2 where change in mobility score is plotted against change in MAHT accuracy score. It can be seen from this scattergram that overall, change in disability is only poorly associated with change in MAHT accuracy

Table 7 Comparisons between high and low change subgroups

\begin{tabular}{|c|c|c|c|c|c|c|c|c|c|c|}
\hline & & \multirow[t]{2}{*}{$\begin{array}{l}\text { Age } \\
\text { (years) }\end{array}$} & \multirow[t]{2}{*}{$\begin{array}{l}\text { Education } \\
\text { (years) }\end{array}$} & \multirow{2}{*}{$\begin{array}{l}\text { Duration of } \\
\text { illness } \\
\text { (years) }\end{array}$} & \multicolumn{2}{|l|}{$\begin{array}{l}\text { Disability } \\
\text { score }\end{array}$} & \multicolumn{2}{|l|}{$\begin{array}{l}\text { MAHT } \\
\text { accuracy }\end{array}$} & \multicolumn{2}{|c|}{$\begin{array}{l}\text { Subjective } \\
\text { affectlarousal }\end{array}$} \\
\hline & & & & & On & off & $O n$ & Off & $O n$ & Off \\
\hline $\begin{array}{l}\text { High change group } \\
(n=5)\end{array}$ & $\begin{array}{l}\text { Mean } \\
\text { SD }\end{array}$ & $\begin{array}{r}61 \cdot 2 \\
7 \cdot 1\end{array}$ & $\begin{array}{r}12 \cdot 4 \\
1 \cdot 9\end{array}$ & $\begin{array}{r}12 \cdot 4 \\
4 \cdot 1\end{array}$ & $\begin{array}{r}15 \cdot 8 \\
4 \cdot 7\end{array}$ & $\begin{array}{l}59 \cdot 4 \\
17 \cdot 8\end{array}$ & $\begin{array}{l}70 \cdot 9 \\
14 \cdot 0\end{array}$ & $\begin{array}{l}57 \cdot 2 \\
13 \cdot 7\end{array}$ & $\begin{array}{r}55 \cdot 2 \\
7 \cdot 3\end{array}$ & $\begin{array}{l}70 \cdot 4 \\
11 \cdot 1\end{array}$ \\
\hline \multirow[t]{2}{*}{$\begin{array}{l}\text { Low change group } \\
(\mathrm{n}=11)\end{array}$} & $\begin{array}{l}\text { Mean } \\
\text { SD }\end{array}$ & $\begin{array}{r}54 \cdot 1 \\
9 \cdot 1\end{array}$ & $\begin{array}{r}11 \cdot 9 \\
3 \cdot 2\end{array}$ & $\begin{array}{r}10.6 \\
4.0\end{array}$ & $\begin{array}{r}12 \cdot 4 \\
6 \cdot 1\end{array}$ & $\begin{array}{l}54 \cdot 8 \\
13 \cdot 6\end{array}$ & $\begin{array}{l}65.9 \\
11.6\end{array}$ & $\begin{array}{l}63 \cdot 1 \\
12 \cdot 8\end{array}$ & $\begin{array}{l}49.3 \\
10.7\end{array}$ & $\begin{array}{l}53 \cdot 6 \\
14 \cdot 1\end{array}$ \\
\hline & & $\begin{array}{l}t=1.55 \\
(\text { df. } 9.4) \\
\text { NS }\end{array}$ & $\begin{array}{l}t=0.35 \\
\text { (df. } 11 \cdot 7 \text { ) } \\
\text { NS }\end{array}$ & $\begin{array}{l}t=0.73 \\
\text { (df. } 7 \cdot 2 \text { ) } \\
\text { NS }\end{array}$ & $\begin{array}{l}t=1 \cdot 16 \\
\text { (df. } 9 \cdot 3 \text { ) } \\
\text { NS }\end{array}$ & $\begin{array}{l}t=0.47 \\
\text { (df. 6.0) } \\
\text { NS }\end{array}$ & $\begin{array}{l}t=0.69 \\
\text { (df. 6.9) } \\
\text { NS }\end{array}$ & $\begin{array}{l}t=0.81 \\
\text { (df. } 7.7 \text { ) } \\
\text { NS }\end{array}$ & $\begin{array}{l}t=1 \cdot 19 \\
\text { (df. 10.7) } \\
\text { NS }\end{array}$ & $\begin{array}{l}t=2.35 \\
\text { (df. } 9.5) \\
p<0.05\end{array}$ \\
\hline
\end{tabular}




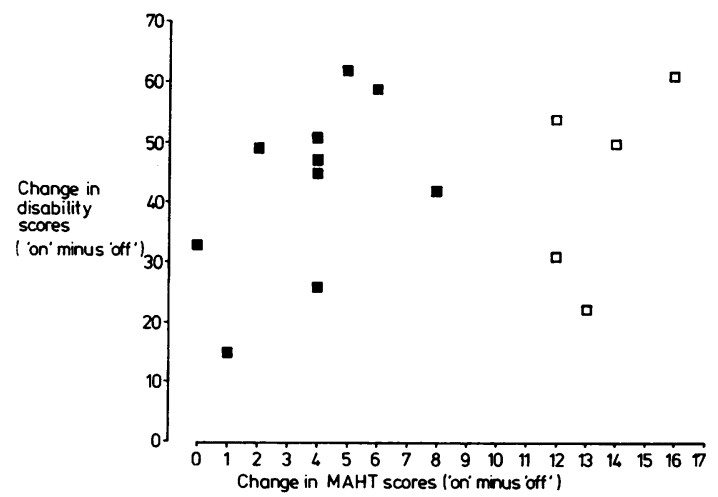

Fig 2 Scattergram of differences in MAHT accuracy scores and degree of motor disability, between the "on" and the "off' conditions. Parkinson's disease group $(N=15)$. (Solid squares: Low change group. Open squares: High change group.)

score $(r=-0 \cdot 08)$. It should be noted that one patient whose MAHT accuracy improved in the "off" condition is excluded from this figure. The most likely reason for this is that his levodopa levels were too high during the "on" testing. This hypothesis is partly confirmed by the severe dyskinesia which was apparent while "on". It is clear from fig 2 that some patients with Parkinson's disease can experience a dramatic loss of mobility without change in this measure of cognitive function. This phenomenon was pointed out previously by one of us (CDM) ${ }^{5152}$ who concluded from this observation that severe changes in striatal dopamine function need not necessarily be associated with parallel cognitive alteration. From this it was speculated that striatal activity may not be associated with cognitive functions. The present data add weight to that speculation. However, as was pointed out in the original publication, such a result might also occur if striatal dopamine deficiency in such patients is confined to a restricted "motor" area of the striatum (in particular, the putamen). Other "non-motor" striatal regions might then be unaffected either by the disease or by levodopa therapy. This result, therefore, does not exclude a cognitive role for striatal function. Detailed neurochemical mapping of striatal dopamine levels in such patients is necessary to settle the point.

\section{Conclusions}

A number of tentative conclusions may be drawn from the results of the present study.

The first is that severe fluctuations in the functional integrity of at least the striatal dopamine sys- tem is not invariably associated with fluctuations in cognitive performance as measured by the present test. Until the mechanism of the "on-off' fluctuations, and the extent to which it affects non-striatal dopamine systems is fully understood, it will be possible only to speculate on the possible contributions played by the mesolimbic and mesocortical dopamine systems to the present findings.

Second, where fluctuations in cognitive function are found, they tend to be relatively mild in nature (compared to the severity of the motor fluctuations) and they are present in only a proportion of individuals.

Finally, if one was forced to name a single factor associated with functional cognitive impairment in the present study, the only real choice would be the disturbance of affect/arousal as assessed by the present measure. This emphasises the importance of investigating such factors as mood, alertness and arousal, both in their own right and as possible determinants of cognitive function.

The authors acknowledge the help of the staff at the Maudsley and King's College Hospitals, to the Department of Experimental Psychology, University of Oxford, to the control subjects who gave up their time, and above all to the sixteen patients who were so willing to cooperate despite the severity of their affliction.

\section{References}

' Wilson RS, Kaszniak AW, Klawans HL, Garron DC. High speed memory scanning in Parkinsonism. Cortex 1980;16:67-72.

${ }^{2}$ Warburton JW. Memory disturbance and Parkinson syndrome. Br J Med Psychol 1967;40:169-71.

${ }^{3}$ Riklan M, Whelihan W, Cullinan T. Levodopa and psychometric test performance in parkinsonism-5 years later. Neurology (Minneap) 1976;26:173-9.

${ }^{4}$ Matison R, Mayeux R, Rosen J, Fahn S. Tip-of-thetongue anomia in Parkinson disease. Neurology (NY) 1982;32:567-70.

5 Bowen FP, Hoehn MM, Yahr MD. A note on alterations of personal orientation in Parkinsonism. Neuropsychologia 1976;14:425-31.

- Bowen FP, Hoehn MM, Yahr MD. Parkinsonism. Alterations in spatial orientation as determined by a route-walking test. Neuropsychologia 1972;10:35561.

' Bowen FP, Kammienny RS, Burns MM, Yahr MD. Parkinsonism: effects of L-dopa treatment on concept formation. Neurology (Minneap) 1975;25:701-4.

${ }^{8}$ Pirozzolo FJ, Hansch EC, Mortimer JA, Webster DD, Kuskowski MA. Dementia in Parkinson's disease: a neuropsychological analysis. Brain and Cognition 1982;1:71-83.

9 Bentin S, Silverburg R, Gordon HW. Asymmetrical 
cognitive deterioration in demented and parkinsonian patients. Cortex 1981;17:533-44.

${ }^{10}$ Bernheimer H, Birkmayer W, Hornykiewicz O, Jellinger $\mathrm{K}$, Seitelberger F. Brain dopamine and the syndromes of Parkinson and Huntington. J Neurol Sci 1973;20:415-55.

"Javoy-Agid F, Agid Y. Is the mesocortical dopaminergic system involved in Parkinson's disease? Neurology (Minneap) 1980;30:1326-30.

12 Moore RY, Bhatnagar RK, Heller A. Anatomical and chemical studies of nigro-neostriatal projection in the cat. Brain Res 1971;30:119-35.

${ }^{13}$ Fallon JH, Riley JH, Moore RY. Substantia nigra dopamine neurons: separate populations project to neostriatum and allocortex. Neurosci Lett 1978; 7:157-62.

14 Thierry AM, Tassin JP, Blanc G, Glowinski J. Studies on mesocortical dopamine systems. Adv Biochem Psychopharmacol 1978;19:205-16.

15 Price KS, Farley IJ, Hornykiewicz O. Neurochemistry of Parkinson's disease: relation between striatal and limbic dopamine. Adv Biochem Psychopharmcol 1978;19:293-300.

${ }^{16}$ Alvord EC, Forno LS, Kusske JA, Kauffman RJ, Rhodes JS, Goetowski CR. The pathology of Parkinsonism: a comparison of degeneration in cerebral cortex and brainstem. Adv Neurol 1974;5:175-93.

${ }^{17}$ Boller F, Mizutani T, Roessman U, Gambetti P. Parkinson disease, dementia and Alzheimer disease: clinicopathological correlations. Ann Neurol 1980; 7:329-35.

${ }^{18}$ Hakim AH, Mathieson G. Dementia in Parkinson's disease: a neuropathologic study. Neurology (Minneap) 1979;29:1209-14.

${ }^{19}$ Schneider E, Fischer P-A, Jacobi P, Becker H, Hacker $H$. The significance of cerebral atrophy for the symptomatology of Parkinson's disease. J Neurol Sci 1979;42:187-97.

${ }^{20}$ Selby G. Cerebral atrophy in Parkinsonism. J Neurol Sci 1968;6:517-59.

${ }^{21}$ Lavy S, Melamed E, Cooper C, Bentin S, Rinot Y. Regional cerebral blood flow in patients with Parkinson's disease. Arch Neurol 1979;36:344-8.

${ }^{22}$ Whitehouse PJ, Price DL, Clark AW, Coyle JT, DeLong MR. Alzheimer disease: evidence for selective loss of cholinergic neurons in the nucleus basalis. Ann Neurol 1981;10:122-6.

${ }^{23}$ Henke H, Lang W. Cholinergic enzymes in neocortex, hippocampus and basal forebrain of non-neurological and senile dementia of Alzheimer-type patients. Brain Res 1983;267:281-91.

24 Whitehouse PJ, Hedreen JC, White CL, Price DL. Basal forebrain neurons in the dementia of Parkinson's disease. Ann Neurol 1983;13:243-8.

${ }^{25}$ Mann DMA, Yates PO. Pathological basis for neurotransmitter changes in Parkinson's disease. Neuropathol Appl Neurobiol 1983;9:3-19.

${ }^{26}$ Marttila RJ, Rinne UK. Dementia in Parkinson disease. Acta Neurol Scand 1976;54:431-41.

${ }^{27}$ Celesia GC, Wanamaker WM. Psychiatric disturbance in Parkinson's disease. Dis Nerv Syst 1972;33:577-83.

${ }^{28}$ Meier MJ, Martin WE. Intellectual changes associated with levodopa therapy. JAMA 1970;213:465-6.

${ }^{29}$ Portin R, Rinne UK. Neuropsychological responses of Parkinsonian patients to long-term levodopa therapy. In: Rinne UK, Klinger M, Stamm G, eds. Parkinson's Disease. Current Progress, Problems and Management. Amsterdam. Elsevier, 1980:270-304.

${ }^{30}$ Marsh GG, Markham CM, Ansel R. Levodopa's awakening effect on patients with parkinsonism. J Neurol Neurosurg Psychiatry 1971;34:209-18.

${ }^{31}$ Garron DC, Klawans HL, Narin F. Intellectual functioning in persons with idiopathic Parkinsonism. J Nerv Ment Dis 1972;154:445-52.

${ }^{32}$ Horn S. Some psychological factors in Parkinsonism. $J$ Neurol Neurosurg Psychiatry 1974;37:27-31.

${ }^{33}$ Danta G, Hilton RC. Judgement of visual vertical and horizontal in patients with parkinsonism. Neurology (Minneap) 1975;25:43-7.

${ }^{34}$ Mortimer JA, Pirozzolo FJ, Hansch EC, Webster DD. Relationship of motor symptoms to intellectual deficits in Parkinson's disease. Neurology (NY) 1982;32:133-7.

${ }^{35}$ Marsden CD. On-off phenomenon in Parkinson disease. In: Rinne UK, Klinger M, Stamm G, eds. Parkinson's Disease: Current Progress, Problems and Management. Amsterdam. Elsevier, 1980:240-53.

${ }^{36}$ Wycis HT, Cunningham W, Kellett G, Spiegel EA. L-dopa in the treatment of post-surgical Parkinson patients. J Neurosurg 1970;32:281-5.

${ }^{37}$ Cotzias GC, Papavasiliou PS, Gellene R. Modification of parkinsonism-chronic treatment with L-dopa. New Engl J Med 1969;280:337-45.

38 Jenkins RB, Groh RH. Mental symptoms in Parkinsonian patients treated with L-dopa. Lancet 1970;2:177-88.

${ }^{39}$ Lieberman A, Dziatolowski M, Kupersmith M, Serby M, Goodgold A, Korein J, Goldstein M. Dementia in Parkinson disease. Ann Neurol 1979;6:355-9.

${ }^{40}$ Mayeux R, Stern Y, Rosen J, Leventhal J. Depression, intellectual impairment and Parkinson disease. Neurology (NY) 1981;31:645-50.

${ }^{41}$ Brown GL, Wilson WP. Parkinsonism and depression. South Med J 1972;65:540-5.

${ }^{42}$ Riklan MD. L-dopa and Parkinsonism. A Psychological Assessment. Springfield Thomas, 1973.

${ }^{43}$ Wechsler D. The Wechsler Adult Intelligence Scale. New York Psychological Corporation, 1955.

${ }^{44}$ Powell GE. The relationship between intelligence and verbal and spatial memory. $J$ Clin Psychol 1979;35:335-40.

${ }^{45}$ Heim AW. An attempt to test high-grade intelligence. Br J Psychol (Gen) 1974;37:70-81.

${ }^{46}$ Bond A, Lader M. The use of analogue scales in rating subjective feeling. Br J Med Psychol 1974;47:211-8.

${ }^{47}$ Kay DWK, Bergmann K. Physical disability and mental health in old age. J Psychosom Res 1966;10:3-12.

${ }^{48}$ Post F. The relationship to physical health of the affective illnesses in the elderly. In: Proceedings 18th International Congress of Gerontology. Washington DC, 1969.

${ }^{49} \mathrm{Nie} \mathrm{NH}$, Hull $\mathrm{CH}$, Jenkins JG, Steinerenner K, Bent DH. SPSS Statistical Package for the Social Sciences. 2nd ed, New York. McGraw Hill, 1970. 
so Tabachnick B, Fidell S. Using Multivariate Statistics. New York: Harper and Row, 1983.

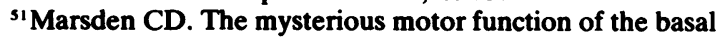

ganglia. Neurology (NY) 1982;32:514-39.

52 Marsden CD. The enigma of the basal ganglia and movement. TINS 1980;3:284-7.

\section{APPENDIX I Example items from the Modified Alice}

Heim Test (MAHT). (Reproduced by permission.

NFER-Nelson (C) 1973.)

(a) Which one of the five words on the right, bears a similar relation to each of the two words on the left?

Dark Heavy

$$
\text { Dull }
$$

Open

$$
\text { Light Fair }
$$

(b)

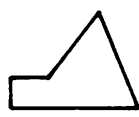

Is the same as.......
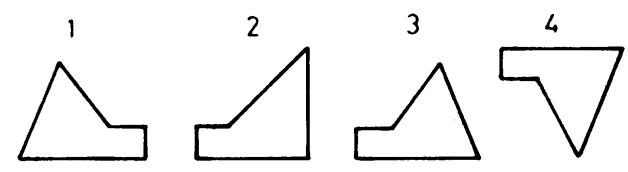

5

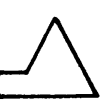

(C) The two figures on the left have a feature in common. One, and only one, of the figures on the right has this feature. Which is it?
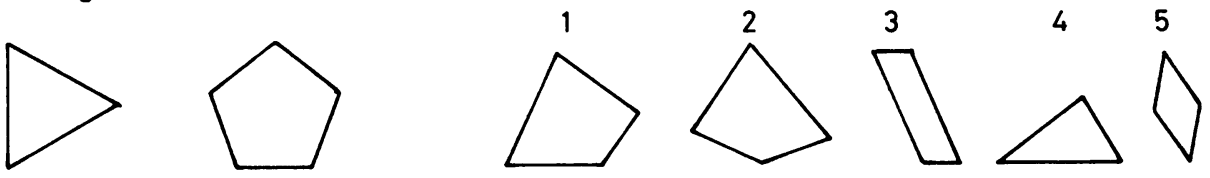

(d)

What is the
$7,1,3,6,2,9,4,5,8$ fifth figure
on the left ?

A B C D $E$

9645 None of these

(e)

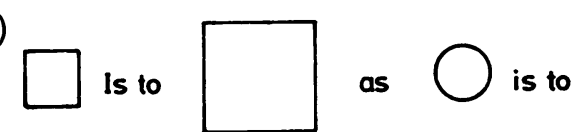

(f)

Big means the opposite of
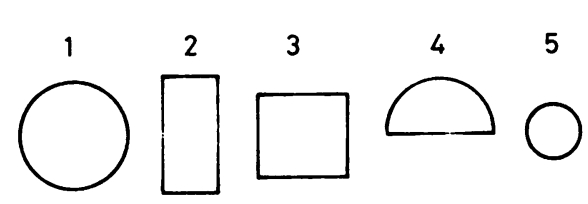

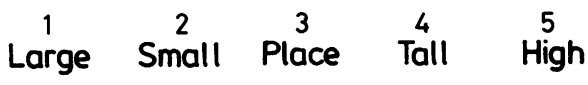

(g) Here are three figures : 594 Subtract the smallest figure from the biggest and multiply the result by the figure printed

A $B$ C $\quad D \quad$ E

$\begin{array}{llll}36 & 20 & 25 & 16\end{array}$ None of these 


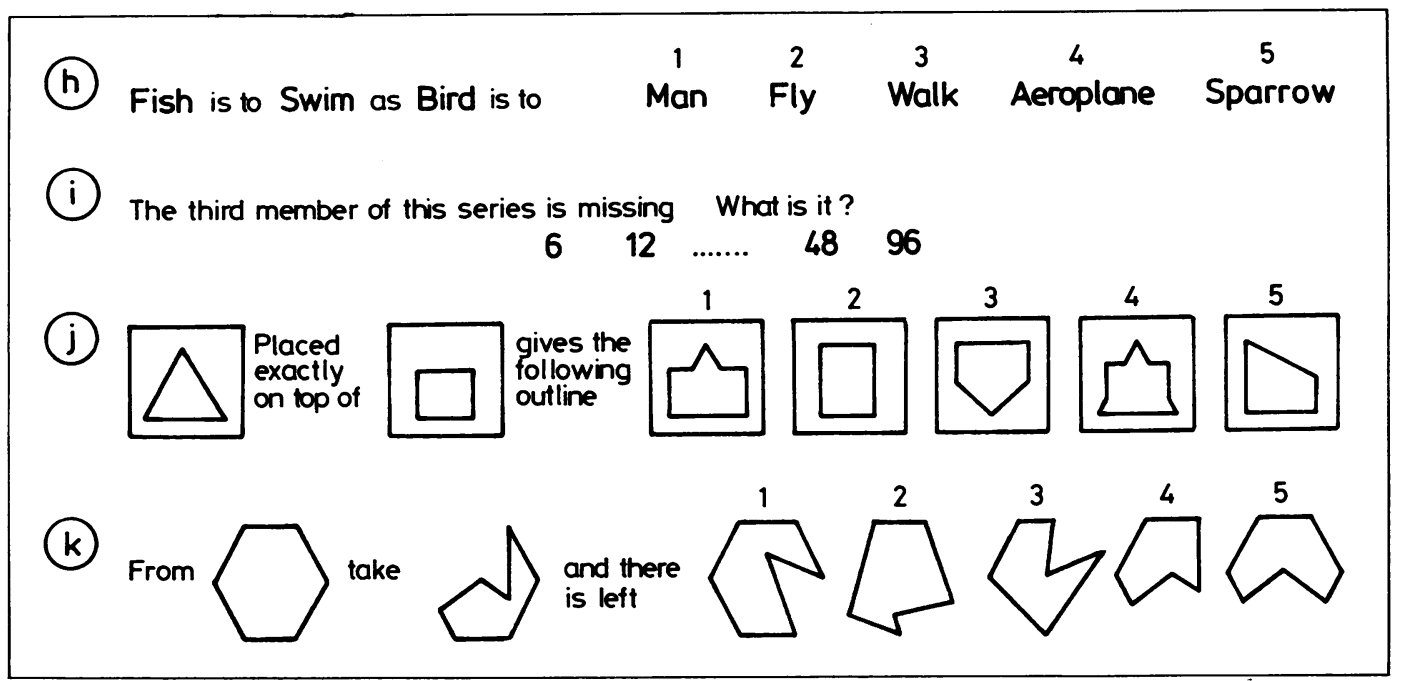

(1.)

15, 35, 55, 75, 95 ....... What number comes next? $105 \quad 125 \quad 110 \quad 115$ None of these

(m)
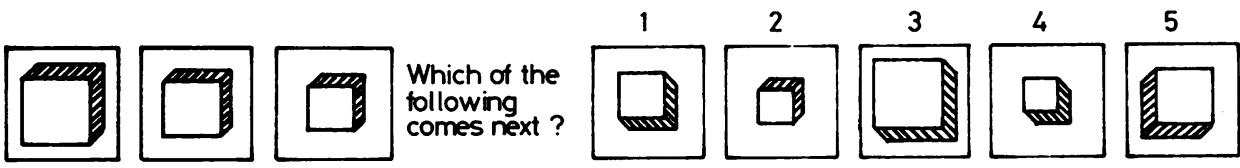

(n) Rich means the same as

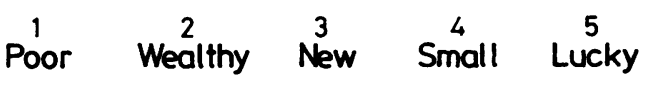

(0) Which one of the figures on the right can be made by joining the dots on the left
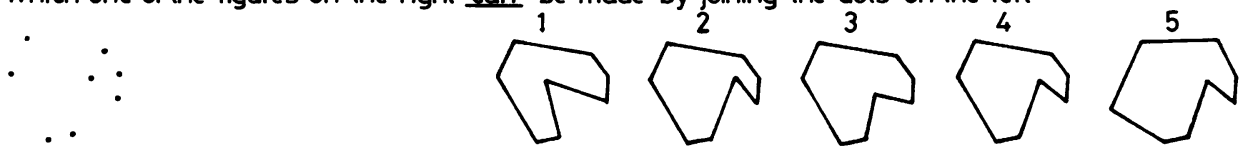

APPENDIX II Visual analogue scales used to assess subjective affect/arousal state. (From Bond and Lader. 1974.)

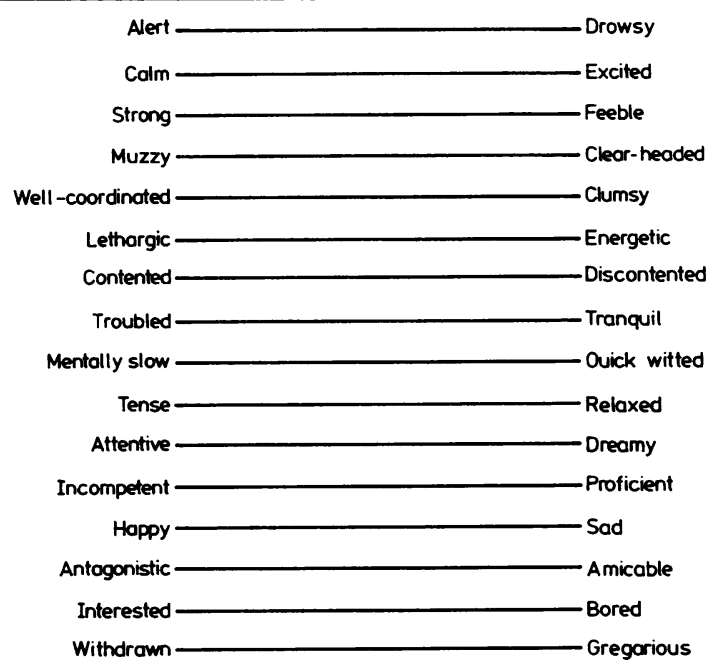

